\title{
Prognostic relevance of demographics and surgical practice for patients with gastric cancer in two centers: in Poland versus Germany
}

\author{
Radoslaw Jaworski • Elfriede Bollschweiler • Arnulf H. Holscher • \\ Stefan P. Monig · Jaroslaw Skokowski · Jacek Zielinski • \\ Maciej Swierblewski $\cdot$ Andrzej Kopacz $\cdot$ Janusz Jaskiewicz
}

Received: 14 July 2010/ Accepted: 13 February 2011/Published online: 26 March 2011

(C) The Author(s) 2011. This article is published with open access at Springerlink.com

\begin{abstract}
Background Although studies comparing the surgical treatment of gastric carcinoma in Japan and Western industrialized countries have revealed differing survival rates, no studies to date have been performed comparing Western and Eastern Europe. This study aimed to compare demographics and surgical practice as well as the related prognostic impact on gastric cancer patients treated in Poland and Germany.

Methods This retrospective study included gastric cancer patients treated between 1999 and 2004 by surgical departments in Gdansk (Poland) and Cologne (Germany). Univariate and multivariate analyses of demographic, histopathological, surgical, and prognostic data were performed.

Results Included were 117 patients from Gdansk and 130 patients from Cologne. The Cologne patients showed higher incidence rates of serious comorbidity, pT1 cancer, and distant metastasis than those from Gdansk. Indications for and frequency of selected surgical procedures differed significantly. D2-lymphadenectomy was performed in $89 \%$ of the Cologne patients, while D1-lymphadenectomy was done for $85 \%$ of the Gdansk patients. Univariate analysis yielded a 5-year survival rate of $28.3 \%$ for the Gdansk patients, and $40.3 \%$ for the Cologne patients $(p=0.056)$.
\end{abstract}

R. Jaworski · J. Skokowski · J. Zielinski - M. Swierblewski ·

A. Kopacz · J. Jaskiewicz

Department of Surgical Oncology,

Medical University of Gdansk, Gdańsk, Poland

E. Bollschweiler $(\bowtie)$ A A. H. Holscher · S. P. Monig Department of General, Visceral and Cancer Surgery,

University of Cologne, Kerpener Str. 62,

50937 Cologne, Germany

e-mail: Elfriede.Bollschweiler@uk-koeln.de
Independent prognostic factors were pT category $(p=$ $0.002)$, pN category $(p<0.001), \mathrm{pM}$ category $(p=0.027)$, residual tumor $(\mathrm{R})$ category $(p=0.004)$, age $(p=0.012)$, and number of resected lymph nodes $(p=0.005)$.

Conclusions Significant differences of clinical and surgical parameters exist between gastric cancer patients treated in Poland and Germany. In addition to established independent prognostic factors, we found that survival improved with each additionally resected lymph node.

Keywords Gastric cancer - Germany · Lymphadenectomy · Poland · Prognosis . Surgical procedures

\section{Introduction}

Gastric cancer is one of the most common malignancies worldwide [1]. Despite decreasing incidence rates in Western industrialized countries, gastric carcinoma remains in the top ten causes of tumor-related death in Germany [2]. The incidence rate of stomach cancer in Poland, also decreasing, is similar to that of Germany, with 16.9 cases per 100,000 population (1993-1997) [3]. Although surgery remains the only curative treatment, the type of operative treatment used for gastric cancer varies geographically [4]. Increased survival may depend on early detection made possible with endoscopy, surgical resection including appropriate lymph node dissection, and improvements in perioperative care. Differing survival rates have been reported for patients receiving surgical intervention in Japan versus those in Western industrialized countries $[5,6]$. However, for patients with gastric cancer, there exists no published prognostic comparison between Eastern and Western Europe. 
The purpose of this study was to compare the characteristics of gastric cancer patients and the prognostic impact between two surgical departments: one in Gdansk (Poland), and the other in Cologne (Germany).

\section{Patients and methods}

\section{Patients}

The period of the study was 1 January 1999 until 31 December 2004. Patients underwent surgery with curative intent for primary gastric cancer. There were 117 patients (90\% of all patients with gastric cancer) in Gdansk (Department of Surgical Oncology, Medical University of Gdansk [Poland]), and 130 patients ( $85 \%$ of all patients with gastric cancer) in Cologne (Department of General, Visceral and Cancer Surgery, University of Cologne [Germany]). Inclusion criteria were: histopathologically confirmed gastric cancer (from gastroscopy), no signs of metastases in preoperative assessment, and operable tumor. In all patients, the preoperative assessment of gastric cancer included not only gastroscopy but also standard laboratory tests, chest $\mathrm{X}$-ray. and thoracic and abdominal computed tomography (CT) scans. Besides, in case of doubt the patients underwent laparoscopy (in Cologne), and a few patients had peritoneal cytology assessment performed. The comorbidity of a patient was classified according the American Society of Anesthesiologists' Physical Status: ASA classification [7, 8]. For both centers the ASA grade assessment was reevaluated by one doctor according to the patient's medical history. Cardiac evaluation was mostly based on reviewing the patient's medical history and assessing the coexistence of coronary disease, arterial hypertension, diabetes mellitus, and the New York Heart Association (NYHA) score. All patients had electrocardiograms performed. Respiratory system evaluation included analysis of the patient's medical history, medical examination of the patient, and chest X-ray. Patients who had a prior history of a respiratory disorder had spirometry performed and its result had an impact on the final ASA score.

\section{Surgical procedures}

In Cologne, the guidelines of the German Society of Surgery were used to evaluate indications for therapy and the selection of the surgical procedure $[9,10]$. Summarized, these guidelines are as follows: endoscopic mucosal resection and submucosal dissection are indicated in superficial cancer confined to the mucosa with special characteristics (T1a/no ulcer/G1,2/Laurén intestinal/L0/V0/tumor size $<2$ $\mathrm{cm})$. In all other cases total gastrectomy or distal subtotal gastric resection are indicated, the latter in cases of tumors located in the distal two-thirds of the stomach. Standard lymphadenectomy (LAD) is the D2-LAD without distal pancreatectomy or splenectomy. Carcinoma in the cardia or upper third of the stomach, classified according to Siewert et al. [11] as type II or III tumors, can be treated by an extended total gastrectomy with a transhiatal resection of the distal esophagus and LAD of the lower mediastinum and the abdominal D2 compartment. Extended organ resections are only indicated in cases where $\mathrm{R} 0$ resection is possible. In Gdansk, the main goal of surgical intervention was the complete removal of tumor. Indications for performing either subtotal gastrectomy, total gastrectomy, or extended total gastrectomy were based on tumor location, histological type, and trial for achieving surgical tumor-free margins. Splenectomy was carried out after iatrogenic stimulus or when there was apparent direct infiltration of tumor. Reconstruction of the digestive tract was performed with either Billroth II reconstruction (after subtotal gastrectomy), or with the Roux-en-Y reconstruction technique.

\section{Histopathology}

Resected specimens were routinely fixed in 5\% phosphatebuffered formalin and embedded in paraffin. Histopathological examination of all resected specimens consisted of a thorough and standardized evaluation of tumor stage, residual tumor (R) category, grading, and number of resected and infiltrated lymph nodes. Postoperative staging was done according to the 6th edition of the International Union Against Cancer (UICC)-TNM classification of malignant tumors [12]. Gastric lymph nodes were documented according to the classification of the Japanese Research Society of Gastric Cancer (JRSGC), with lymph node groups 1-13. Tumor localization was defined according to the International Classification of Diseases for Oncology. Lesions were further classified and graded in accordance with the WHO recommendations, the Laurén classification, and tumor differentiation (G1-G4) [13].

\section{Statistical analysis}

Data were collected and analyzed retrospectively. Descriptive analysis included the frequency of nominal parameters, the median with the lower quartile (LQ) and upper quartile (UQ) for numeric variables (ordinal or asymmetric distribution), and the mean for numeric variables with normal distribution. Univariate analysis was calculated for tables using $\chi^{2}$ statistics with the Yates correction or Fisher's exact test if necessary. The MannWhitney $U$-test was used to compare continuous variables.

More than $90 \%$ of the patients had a follow-up duration longer than four years. There was no difference of follow-up between the two centers. Univariate survival analysis was 
conducted according to Kaplan-Meier, and survival curves were compared with the log rank test [14]. In addition, the hazard ratio with the $95 \%$ confidence interval $(95 \% \mathrm{CI})$ was calculated. Multivariate analysis was performed by the Cox regression method, using the backward option, meaning: first enter all variables into the model and then remove nonsignificant variables sequentially. Assuming that the hazard function for Gdansk was different from that for Cologne over time, we stratified according to center [15].

Statistical significance was set at $p<0.05$. For statistical analysis, the SPSS for Windows (version 17.0) application (SPSS, Chicago IL, USA) was used. For graphical presentation of the survival curve, the statistical program MedCalc for Windows Version 11.4 (MedCalc Software, Mariakerke, Belgium) was used.

\section{Results}

\section{Demographics}

There were 117 gastric cancer patients from Gdansk and 130 from Cologne. The proportion of females was significantly $(p=0.019)$ higher in the Polish group (41.9\%) compared to the German group (27.7\%). Patients from Gdansk were younger, with a median age of 63.9 years compared to those from Germany (median 66.8 years); however, the difference was not statistically significant $(p=0.212)$. Cologne patients had significantly $(p<0.001)$ more severe comorbidities (ASA III and IV) than patients in Gdansk. The demographic characteristics are shown in Table 1.
Table 1 Demographic and histopathological data from patients treated surgically for gastric carcinoma from Gdansk (Poland) and Cologne

(Germany)
ASA anesthesia risk according to American Society of Anesthesiologists [7, 8], pT tumor infiltration depth into gastric wall, $p N$ lymph node status, $p M O$ no distant metastases, $p M 1$ distant metastases

\begin{tabular}{|c|c|c|c|}
\hline Feature & $\begin{array}{l}\text { Gdansk, Poland } \\
(n=117)\end{array}$ & $\begin{array}{l}\text { Cologne, Germany } \\
(n=130)\end{array}$ & $p$ value \\
\hline \multicolumn{4}{|l|}{ Demographics } \\
\hline \multicolumn{4}{|l|}{ Gender } \\
\hline Males & $68(58.1 \%)$ & $94(72.3 \%)$ & \multirow[t]{2}{*}{0.019} \\
\hline Females & $49(41.9 \%)$ & $36(27.7 \%)$ & \\
\hline \multicolumn{4}{|l|}{ Median age (min-max) } \\
\hline All patients & 63.9 years ( $26-88$ years) & 66.8 years $(31-87$ years $)$ & 0.212 \\
\hline Males & 63.3 years & 66.7 years & 0.063 \\
\hline Females & 67.8 years & 67.0 years & 0.972 \\
\hline \multicolumn{4}{|l|}{ Comorbidities } \\
\hline ASA I and II & $77(65.5 \%)$ & $51(39.0 \%)$ & \multirow[t]{2}{*}{$<0.001$} \\
\hline ASA III and IV & $40(34.5 \%)$ & $79(61.0 \%)$ & \\
\hline \multicolumn{4}{|l|}{ Histopathology } \\
\hline \multicolumn{4}{|l|}{ Tumor localization } \\
\hline Upper third & $43(36.8 \%)$ & $59(45.4 \%)$ & \multirow[t]{3}{*}{0.356} \\
\hline Middle third & $41(35.0 \%)$ & $37(28.5 \%)$ & \\
\hline Lower third & $33(28.2 \%)$ & $34(26.2 \%)$ & \\
\hline \multicolumn{4}{|l|}{ Type of histopathology (WHO) } \\
\hline Adenocarcinoma & $100(85.3 \%)$ & $82(63.2 \%)$ & \multirow[t]{3}{*}{$<0.001$} \\
\hline Signet-ring cell carcinoma & $16(13.7 \%)$ & $45(34.4 \%)$ & \\
\hline Other histology & $1(1.0 \%)$ & $3(2.4 \%)$ & \\
\hline \multicolumn{4}{|l|}{ pT category } \\
\hline pT1 & $6(4.8 \%)$ & $29(22.3 \%)$ & \multirow[t]{4}{*}{$<0.001$} \\
\hline pT2 & $22(19.0 \%)$ & $28(21.5 \%)$ & \\
\hline pT3 & $72(61.9 \%)$ & $37(28.5 \%)$ & \\
\hline pT4 & $17(14.3 \%)$ & $36(27.7 \%)$ & \\
\hline \multicolumn{4}{|l|}{ pN category } \\
\hline pNO & $37(31.3 \%)$ & $44(33.8 \%)$ & \multirow[t]{4}{*}{0.339} \\
\hline pN1 & $42(35.7 \%)$ & $41(31.5 \%)$ & \\
\hline $\mathrm{pN} 2$ & $29(25.0 \%)$ & $26(20.0 \%)$ & \\
\hline $\mathrm{pN} 3$ & $9(8.0 \%)$ & $19(14.6 \%)$ & \\
\hline \multicolumn{4}{|l|}{ pM category } \\
\hline pM0 & $100(85.6 \%)$ & $93(71.5 \%)$ & \multirow[t]{2}{*}{0.009} \\
\hline pM1 & $17(14.4 \%)$ & $37(28.5 \%)$ & \\
\hline
\end{tabular}


Histopathology

The tumor was located in the upper third of the stomach for nearly half of the patients in both clinics. There was no significant difference in tumor localization. Signet-ring cell carcinoma histology was diagnosed significantly $(p<0.001)$ more often in patients from Cologne $(34.4 \%)$ versus those from Gdansk (13.7\%). In contrast, the Polish patients showed significantly $(p<0.001)$ more advanced pT categories than the German patients. At a rate of only $5 \%$, early cancer was a rare diagnosis in Gdansk, in contrast to the Cologne group, where the frequency was $22 \%$ $(p<0.001)$. More details are provided in Table 1 .

\section{Surgical treatment}

The details of surgical practice are listed in Table 2. Procedure frequency and indications for the various interventions differed between the two clinics. The 30- and 90-day mortality rates did not differ between the clinics, at 0.9 and 5.9\% in Gdansk versus 2.3 and $4.6 \%$ in Cologne.

\section{Prognosis}

Univariate analysis identified no significant difference in prognosis between the two surgical departments (Table 3). The estimated 5-year overall survival rate for patients from Gdansk was $28.3 \%$ and that for patients from Cologne was $40.3 \%(p=0.056)$, with a hazard ratio of $0.71(95 \%$ CI 0.54-1.01) (Fig. 1). In the univariate analysis performed separately for each center, the following prognostic factors were identified as significant for both centers: clear surgical resection margin (R0 category), $\mathrm{pT}, \mathrm{pN}$, and $\mathrm{pM}$ category $(p<0.001$ for each). In Cologne, there was improved survival in younger ( $<60$ years) versus older patients ( $\geq 60$ years) $(p=0.021)$. For patients from Gdansk, tumor localization $(p=0.012)$, histological tumor type $(p=$ 0.001 ), and type of lymphadenectomy performed ( $p=$ 0.031 ) had prognostic relevance. The following parameters did not influence survival in either clinic: gender, comorbidity (ASA I and II vs. III and IV), type of gastric resection, and splenectomy.

On comparison of the clinics, parameters responsible for the better prognosis in Cologne were healthy baseline status (ASA I or II), signet-ring cell carcinoma histology, and absence of distant metastasis (Table 3).

The most relevant prognostic factors from the univariate survival analysis were used for multivariate analysis: $\mathrm{pT}, \mathrm{pN}, \mathrm{pM}$, and $\mathrm{R}$ category. In addition, the parameters age (continuous variable), gender, comorbidity, tumor localization, histology, and the number of resected lymph nodes (continuous variable) were included. Cox regression analysis was stratified according to surgical department. Table 4 shows the independent prognostic factors. The established independent prognostic factors, $\mathrm{pT}, \mathrm{pN}$, $\mathrm{pM}$, and R category, were confirmed with our analysis. Patient age was an independent prognostic factor, with a hazard ratio of 1.022 for each subsequent year. As well, each additional resected lymph node improved the prognosis.
Table 2 Surgical treatment of patients with gastric cancer from Gdansk (Poland) and Cologne (Germany)
$R O$ no residual tumor resection, $R 1$ microscopic residual tumor resection, $R 2$ macroscopic residual tumor resection, $D 1$ limited lymph node dissection group, $D 2$ extended lymph node dissection group

\begin{tabular}{lccc}
\hline Feature & $\begin{array}{l}\text { Gdansk, Poland } \\
(n=117)\end{array}$ & $\begin{array}{l}\text { Cologne, Germany } \\
(n=130)\end{array}$ & $p$ value \\
\hline Type of resection & $14(11.8 \%)$ & $17(13.4 \%)$ & $<0.001$ \\
$\quad$ Subtotal gastrectomy & $82(70.0 \%)$ & $40(30.7 \%)$ & \\
Total gastrectomy & $20(17.3 \%)$ & $36(27.6 \%)$ & \\
Extended gastrectomy & $0(0 \%)$ & $36(27.6 \%)$ & $<(0.8 \%)$ \\
Transhiatal extended gastrectomy & $1(0.9 \%)$ & $26(19.8 \%)$ & 0.389 \\
Others & $67(57.1 \%)$ & $119(91.5 \%)$ & $11(8.5 \%)$ \\
Splenectomy & $103(87.7 \%)$ & $14(10.6 \%)$ & $<0.001$ \\
Splenectomy during gastrectomy & $14(12.3 \%)$ & $116(89.4 \%)$ & \\
R0 resection & & $33.5(3-82)$ & $<0.001$ \\
R0 & $99(84.8 \%)$ & $3.0(0-43)$ & 0.948 \\
R1/R2 & $18(15.2 \%)$ & \\
Lymphadenectomy & $13.0(0-47)$ & & \\
D1 & $3.0(0-41)$ & & \\
D2 & & & \\
Number of resected lymph nodes & & & \\
Median (min-max) & & & \\
Number of metastatic lymph nodes & & & \\
Median (min-max) & & & \\
\hline
\end{tabular}


Table 3 Univariate survival analysis comparing the impact of demographic and histopathological factors between 117 patients with gastric cancer from Gdansk (Poland) and 130 patients from Cologne (Germany)

\begin{tabular}{|c|c|c|c|c|c|}
\hline $\begin{array}{l}\text { Univariate survival analysis: } \\
5 \text { year survival rate }\end{array}$ & $\begin{array}{l}\text { Gdansk, Poland } \\
(n=117)(\%)\end{array}$ & $p$ value & $\begin{array}{l}\text { Cologne, Germany } \\
(n=130)(\%)\end{array}$ & $p$ value & $\begin{array}{l}p \text { value between } \\
\text { the two centers }\end{array}$ \\
\hline \multicolumn{6}{|l|}{ Gender } \\
\hline Male & 30.1 & \multirow[t]{2}{*}{0.388} & 42.3 & \multirow[t]{2}{*}{0.962} & 0.168 \\
\hline Female & 20.4 & & 35.2 & & 0.336 \\
\hline \multicolumn{6}{|l|}{ Comorbidities } \\
\hline ASA I and II & 26.5 & \multirow[t]{2}{*}{0.691} & 47.3 & \multirow[t]{2}{*}{0.102} & 0.017 \\
\hline ASA III and IV & 30.7 & & 36.1 & & 0.781 \\
\hline \multicolumn{6}{|l|}{ Tumor localization } \\
\hline Upper third & 32.9 & \multirow[t]{3}{*}{0.012} & 42.1 & \multirow[t]{3}{*}{0.524} & 0.325 \\
\hline Middle third & 14.6 & & 32.1 & & 0.202 \\
\hline Lower third & 40.1 & & 47.1 & & 0.529 \\
\hline \multicolumn{6}{|l|}{ Histopathological classification (WHO) } \\
\hline Adenocarcinoma (except for signet-ring cell cancer) & 32.2 & \multirow[t]{2}{*}{0.001} & 39.9 & \multirow[t]{2}{*}{0.524} & 0.237 \\
\hline Signet-ring cell cancer & 0.0 & & 39.9 & & 0.007 \\
\hline \multicolumn{6}{|l|}{ pT category } \\
\hline pT1 & - & \multirow[t]{4}{*}{$<0.001$} & 64.4 & \multirow[t]{4}{*}{$<0.001$} & - \\
\hline pT2 & 45.2 & & 46.7 & & 0.928 \\
\hline pT3 & 18.7 & & 35.8 & & 0.271 \\
\hline pT4 & 0.0 & & 18.7 & & 0.201 \\
\hline \multicolumn{6}{|l|}{ pN category } \\
\hline pNO & 59.5 & \multirow[t]{4}{*}{$<0.001$} & 63.1 & \multirow[t]{4}{*}{$<0.001$} & 0.592 \\
\hline $\mathrm{pN} 1$ & 20.4 & & 44.4 & & 0.079 \\
\hline $\mathrm{pN} 2$ & 0.0 & & 13.4 & & 0.079 \\
\hline $\mathrm{pN} 3$ & 0.0 & & 13.0 & & 0.916 \\
\hline \multicolumn{6}{|l|}{ pM category } \\
\hline pM0 & 32.0 & \multirow[t]{2}{*}{$<0.001$} & 53.9 & \multirow[t]{2}{*}{$<0.001$} & 0.013 \\
\hline pM1 & 0.0 & & 8.5 & & 0.175 \\
\hline \multicolumn{6}{|l|}{ R category } \\
\hline $\mathrm{R} 0$ & 31.6 & \multirow[t]{2}{*}{$<0.001$} & 41.8 & \multirow[t]{2}{*}{$<0.001$} & 0.179 \\
\hline $\mathrm{R} 1 / \mathrm{R} 2$ & 0 & & 0 & & 0.107 \\
\hline \multicolumn{6}{|l|}{ Type of gastric resection } \\
\hline Subtotal resection & 44.0 & \multirow[t]{4}{*}{0.116} & 50.4 & \multirow[t]{4}{*}{0.829} & 0.752 \\
\hline Total gastrectomy & 29.9 & & 34.1 & & 0.437 \\
\hline Extended gastrectomy & 15.8 & & 24.0 & & 0.314 \\
\hline Transhiatal extended gastrectomy & - & & 52.2 & & - \\
\hline Lymphadenectomy & & & & & \\
\hline D1 & 25.1 & 0.031 & 19.2 & 0.165 & 0.804 \\
\hline D2 & 47.1 & & 42.8 & & 0.521 \\
\hline
\end{tabular}

ASA anesthesia risk according to American Society of Anesthesiologists [7, 8], $p T$ tumor infiltration depth into gastric wall, $p N$ lymph node status, $p M O$ no distant metastases, $p M 1$ distant metastases, $R$ category: $R O$ no residual tumor resection, $R 1$ microscopic residual tumor resection, $R 2$ macroscopic residual tumor resection, $D 1$ limited lymph node dissection group, $D 2$ extended lymph node dissection group

\section{Discussion}

The patient populations from the two clinics studied here were clearly quite different. Not only did demographic and tumor characteristics vary, but also the indications for choice of therapy and the radicality of surgical intervention performed varied. Despite these differences, established independent prognostic factors for gastric carcinoma, such as depth of tumor infiltration, extent of lymph node metastasis, and presence of distant metastasis, as well as R0 resection, were reconfirmed by our results. The importance of these prognostic factors for the comparison between 


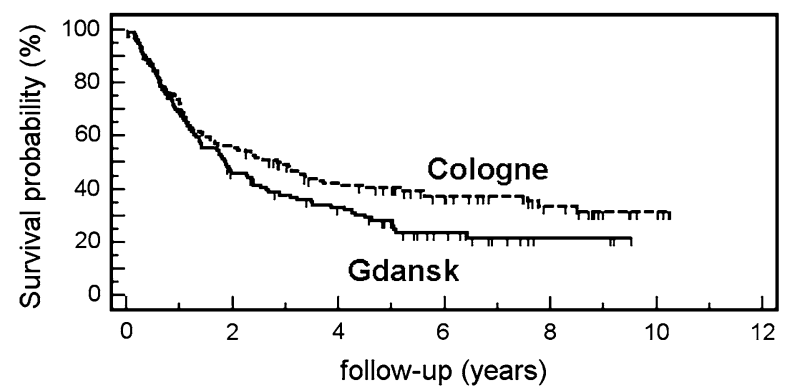

Number at risk

Gdansk

$\begin{array}{cccccccc} & 117 & 52 & 34 & 14 & 3 & 0 & 0 \\ \text { Cologne } & & & & & & & \\ & 130 & 72 & 47 & 31 & 17 & 4 & 1\end{array}$

Fig. 1 Comparison of survival curves of gastric cancer patients from Gdansk (Poland) and from Cologne (Germany) $[p=0.056$; hazard ratio $0.71(95 \%$ confidence interval $[\mathrm{CI}] 0.54-1.01)]$

Table 4 Multivariate survival analysis of independent prognostic factors for patients with surgically treated gastric carcinoma

\begin{tabular}{lllr}
\hline Feature & Hazard ratio & $95 \%$ CI & $p$ value \\
\hline Age & & & \\
Each year & 1.022 & 1.005 & 0.012 \\
pT category & & & 0.002 \\
pT1-pT2 & 1.45 & $0.64-3.30$ & 0.379 \\
pT1-pT3 & 2.83 & $1.34-5.93$ & 0.006 \\
pT1-pT4 & 3.19 & $1.43-7.13$ & 0.005 \\
pN category & & & $<0.001$ \\
pN0-pN1 & 2.36 & $1.37-4.08$ & 0.002 \\
pN0-pN2 & 3.08 & $1.73-5.49$ & $<0.001$ \\
pN0-pN3 & 8.82 & $4.10-18.98$ & $<0.001$ \\
Number of resected LNs & & \\
Each LN & 0.979 & $0.97-0.99$ & 0.005 \\
pM category & & & 0.027 \\
pM0-pM1 & 1.81 & $1.07-3.06$ & \\
R category & & & 0.004 \\
R0-R1/R2 & 2.42 & $1.32-4.45$ &
\end{tabular}

$C I$ confidence interval, $p T$ tumor infiltration depth into gastric wall, $p N$ lymph node status, $p M O$ no distant metastases, $p M 1$ distant metastases, $L N$ lymph node, $R$ category: $R O$ no residual tumor resection, $R 1$ microscopic residual tumor resection, $R 2$ macroscopic residual tumor resection (according to the 6th edition of the International Union Against Cancer (UICC)-TNM classification of malignant tumors [12])

nations has already been reported in studies comparing Japan and Western industrialized nations [5, 6]. Depth of tumor infiltration and the extent of metastasis, as well as the possibility for an R0 resection selected from suitable surgical procedures, are clinical features that patients possess before entering a clinic. This applies also for the age of the patient. In contrast are the frequency of successful R0 resections and the extent of lymphadenectomies performed, which are determined at least partially by the operating surgeon.

In terms of patient-related factors, there were more women in Gdansk than in Cologne who were subjected to surgery for gastric carcinoma. It is possible that this represents a selection bias, because the incidence of gastric carcinoma in women in the two countries does not differ. Age and comorbidity also affect prognosis [16]. Although the age distribution at the two clinics did not differ, presentation of the illness later in life does decrease life expectancy. Age also correlates with the severity of comorbidities, a fact that could explain why more severe comorbidity appears to have no prognostic relevance [17]. Furthermore, the parameter chosen here, the ASA classification, is a nonspecific measure to estimate prognosis [18].

The main difference in clinicopathological features was seen in the depth of tumor invasion into the gastric wall. Early gastric cancer was more prevalent in Cologne than in Gdansk. This correlates with data published by the Polish Gastric Cancer Study Group and the "German Gastric Cancer Study, for Gdansk and Cologne, respectively [1921]. We believe that the observed differences in tumor stage frequency are secondary to varying schools of thought in German society and Polish society, as well as differences in national health policies. There is probably less access to gastroscopy in Poland than in Germany, and perhaps Polish patients do not immediately visit general practitioners with the first symptoms of gastric disease. Although there were differences between the clinics in the tumor stage assessed at time of operation, the tumor stage distribution among our patients was nothing like that observed in Japan, where $56-65 \%$ of all gastric cancers are stage I [22]. This suggests that all European Union countries must take more care to achieve earlier diagnosis.

Surgeon-dependent factors include the selection of surgical therapy and the radicality of the tumor resection performed. In Germany, clear guidelines for the therapeutic approach to gastric cancer exist [10]. As a consequence, different indications were used by the two clinics to determine the types of resection and lymphadenectomy performed and the need for splenectomy, as well as the number of resected lymph nodes.

One of the most important prognostic factors was the number of resected lymph nodes. Each additional resected lymph node improved the probability of survival. These results correspond to other reports in the literature [22]. Peyre et al. [23] found similar results for patients with adenocarcinoma of the esophagus or gastric cardia in an international study assessing the impact of the extent of surgical resection.

Controversy regarding the optimal extent of lymph node dissection continues worldwide [24]. An extended lymph 
node dissection is thought to provide more appropriate pathological staging and better regional disease control, as well as possible survival advantages compared to limited lymph node dissection [25]. Two recent prospective, randomized European trials (in The Netherlands and the United Kingdom) were designed to evaluate whether extended lymphadenectomy improves overall survival. Neither study identified a difference in survival rates. However, the results of both studies were influenced by increased postoperative morbidity/mortality rates associated with increased rates of splenectomy and pancreatectomy in patients undergoing D2-dissection [26-29]. In a review study, McCulloch et al. concluded that the question of extended versus limited lymph node dissection has not yet been decided [30].

The fact that $57 \%$ of Gdansk patients had splenectomy performed during gastrectomy came out as an unanticipated observation. It was related to the conviction that removal of the lymph nodes located in the splenic hilum may be a prognostic marker. Several studies have concluded that the disadvantages of splenectomy outweigh the prognostic benefits for patients with gastric cancer [22, 31, 32]. The results of our analysis convinced the Gdansk surgical team to change the strategy of management and to improve the surgical quality [33]. Currently, the rate of splenectomies in Gdansk does not exceed $20 \%$.

\section{Conclusions}

Despite differences in the frequencies of various prognostic factors between Polish and German gastric carcinoma patients, established prognostic factors such as the depth of tumor infiltration, the existence of lymph node or distant metastasis, and complete removal of the tumor were verified by our results. Of interest is the simultaneous emergence, at the two study centers, of the number of removed lymph nodes as an independent prognostic factor.

Open Access This article is distributed under the terms of the Creative Commons Attribution Noncommercial License which permits any noncommercial use, distribution, and reproduction in any medium, provided the original author(s) and source are credited.

\section{References}

1. Parkin D, Bray F, Ferlay J, Pisani P. Global cancer statistics, 2002. CA Cancer J Clin. 2005;55:74-108.

2. Bollschweiler E, Holscher A. Carcinoma of the esophagusactual epidemiology in Germany. Onkologie. 2001;24:180-4.

3. Lissowska J, Gail M, Pee D, Groves FD, Sobin LH, NasierowskaGuttmejer A, et al. Diet and stomach cancer risk in Warsaw, Poland. Nutr Cancer. 2004;48:149-59.
4. Kovoor P, Hwang J. Treatment of resectable gastric cancer: current standards of care. Expert Rev Anticancer Ther. 2009;9: $135-42$.

5. Bollschweiler E, Boettcher K, Hoelscher A, Sasako M, Kinoshita $\mathrm{T}$, Maruyama $\mathrm{K}$, et al. Is the prognosis for Japanese and German patients with gastric cancer really different? Cancer. 1993;71: 2918-25.

6. Bonenkamp J, van de Velde CJH, Kampschoer G, Hermans J, Hermanek P, Bemelmans M, et al. Comparison of factors influencing the prognosis of Japanese, German, and Dutch gastric cancer patients. World J Surg. 1993;17:410-14 (discussion 415).

7. Menke H, Klein A, John K, Junginger T. Predictive value of ASA classification for the assessment of the perioperative risk. Int Surg. 1993;78:266-70.

8. Davenport D, Bowe E, Henderson W, Khuri SF, Mentzer RM. National Surgical Quality Improvement Program (NSQIP) risk factors can be used to validate American Society of Anesthesiologists Physical Status Classification (ASA PS) levels. Ann Surg. 2006;243:636-41 (discussion 641-44).

9. Moenig S, Baldus S, Bollschweiler E, Hölscher A. Surgery of gastric cancer-quality assurance. Viszeralchirurgie. 2005;42: $42-8$.

10. Grundmann R, Hölscher A, Bembenek A, Bollschweiler E, Drognitz O, Feuerbach S, et al. Diagnosis of and therapy for gastric cancer-work-flow. Zentralbl Chir. 2009;134:362-76.

11. Siewert J, Hölscher A, Becker K, Gossner W. Kardiakarzinom. Versuch einer therapeutisch relevanten Klassifikation. Chirurg. 1987;58:25-9.

12. Sobin L, Wittekind C. UICC (2002) TNM classification of malignant tumors. 6th ed. New York: Wiley; 2002.

13. Japanese Research Society of Gastric Cancer (JRSGC). Japanese classification of gastric carcinoma. 2nd English Edn. Gastric Cancer. 1998;1:10-24.

14. Kaplan E, Meier P. Nonparametric estimation from incomplete observations. J Am Stat Assoc. 1958;53:457-9.

15. Bollschweiler E. Benefits and limitations of Kaplan-Meier calculations of survival chance in cancer surgery. Langenbecks Arch Surg. 2003;388:239-44.

16. Bollschweiler E, Breckheimer S, Monig S, Holscher AH. The prognostic relevance of age and comorbidity in patients with resected gastric cancer. Zentralbl Chir. 2009;134:71-6.

17. Bollschweiler E, Lubke T, Monig S, Holscher A. Evaluation of POSSUM scoring system in patients with gastric cancer undergoing D2-gastrectomy. BMC Surg. 2005;5:8.

18. Popiela T, Kulig J, Kolodziejczyk P, Sierzega M. Changing patterns of gastric carcinoma over the past two decades in a single institution: clinicopathological findings in 1557 patients. Scand J Gastroenterol. 2002;37:561-7.

19. Popiela T, Kulig J, Kolodziejcyk P. Twenty-year experience with multimodal treatment of gastric cancer patients in Poland. Zentrbl Chir. 2001;126:763-71.

20. Siewert J, Bottcher K, Stein H, Roder J. Relevant prognostic factors in gastric cancer: ten-year results of the German Gastric Cancer Study. Ann Surg. 1998;228:449-61.

21. Noguchi Y, Yoshikawa T, Tsuburaya A, Motohashi H, Karpeh MS, Brennan MF. Is gastric carcinoma different between Japan and the United States? Cancer. 2000;89:2237-46.

22. Cheong O, Kim B, Yook J, Park YK, Ryu SY. Modified radical lymphadenectomy without splenectomy in patients with proximal gastric cancer: comparison with standard D2 lymphadenectomy for distal gastric cancer. J Surg Oncol. 2008;98:500-4.

23. Peyre C, Hagen J, De Meester S, Altorki NK, Ancona E, Griffin $\mathrm{SM}$, et al. The number of lymph nodes removed predicts survival in esophageal cancer: an international study on the impact of extent of surgical resection. Ann Surg. 2008;248:549-56. 
24. Shukla P, Pavoor R, Barreto G. Gastric cancer in Europe (Br J Surg 2008; 95: 406-408). Br J Surg. 2008;95:1189 (author reply 1189).

25. Holscher A, Bollschweiler E, Metzger R, Monig S. D2 lymphadenectomy superior to D1 lymphadenectomy in gastric cancer surgery. Zentralbl Chir. 2003;128:786-7.

26. Bonenkamp J, Hermans J, Sasako M, van de Velde CJH. Extended lymph-node dissection for gastric cancer. N Engl $\mathrm{J}$ Med. 1999;340:908-14.

27. Cuschieri A, Fayers P, Fielding J, Craven J, Bancewicz J, Joypaul $\mathrm{V}$, et al. Postoperative morbidity and mortality after D1 and D2 resections for gastric cancer: preliminary results of the MRC randomised controlled surgical trial. The Surgical Cooperative Group. Lancet. 1996;347:995-9.

28. Cuschieri A, Weeden S, Fielding J, Bancewicz J, Craven J, Joypaul V, et al. Patient survival after D1 and D2 resections for gastric cancer: long-term results of the MRC randomized surgical trial. Surgical Co-operative Group. Br J Cancer. 1999;79: 1522-30.
29. Hartgrink H, van de Velde CJ, Putter H, Bonenkamp JJ, Kranenbarg EK, Songum I, et al. Extended lymph node dissection for gastric cancer: who may benefit? Final results of the randomized Dutch gastric cancer group trial. J Clin Oncol. 2004;22:2069-77.

30. McCulloch P, Nita M, Kazi H, Gama-Rodrigues J. Extended versus limited lymph node dissection technique for adenocarcinoma of the stomach. Cochrane Database Syst Rev. 2004;(4).

31. Oh S, Hyung W, Li C, Song J, Kang W, Rha SY, et al. The effect of spleen-preserving lymphadenectomy on surgical outcomes of locally advanced proximal gastric cancer. J Surg Oncol. 2009; 99:275-80.

32. Monig S, Collet P, Baldus S, Schamcpfeffer K, Schroder W, Thiele J, et al. Splenectomy in proximal gastric cancer: frequency of lymph node metastasis to the splenic hilus. J Surg Oncol. 2001;76:89-92.

33. Krijnen P, den Dulk M, Meershoek-Klein KE, Jansen-Landheer ML, van de Velde CJH. Improved survival after resectable noncardia gastric cancer in The Netherlands: the importance of surgical training and quality control. Eur J Surg Oncol. 2009;35:715-20. 